\title{
The influence of the built environment on outcomes from a "walking school bus study": a cross-sectional analysis using geographical information systems
}

\author{
Nicolas M. Oreskovic ${ }^{1,2,3}$, Jeff Blossom ${ }^{4}$, Alyssa I. Robinson ${ }^{1}$, Minghua L. Chen ${ }^{1}$, Doris K. \\ Uscanga $^{5}$, Jason A. Mendoza ${ }^{5,6}$ \\ ${ }^{1}$ Center for Child and Adolescent Health Research and Policy, Massachusetts General Hospital, Boston, USA; \\ ${ }^{2}$ Departments of Internal Medicine and Pediatrics, Massachusetts General Hospital, Boston, USA; ${ }^{3}$ Harvard \\ Medical School, Boston, USA; ${ }^{4}$ Harvard Center for Geographic Analysis, Cambridge, USA; ${ }^{5}$ Seattle Children's \\ Research Institute, Seattle Children's Hospital, Seattle, USA; ${ }^{6}$ University of Washington, Seattle, USA
}

\begin{abstract}
Active commuting to school increases children's daily physical activity. The built environment is associated with children's physical activity levels in cross-sectional studies. This study examined the role of the built environment on the outcomes of a "walking school bus" study. Geographical information systems was used to map out and compare the built environments around schools participating in a pilot walking school bus randomised controlled trial, as well as along school routes. Multi-level modelling was used to determine the built environment attributes associated with the outcomes of active commuting to school and accelerometer-determined moderate-to-vigorous physical activity (MPVA). There were no differences in the surrounding built environments of control $(n=4)$ and intervention $(n=4)$ schools participating in the walking school bus study. Among school walking routes, park space was inversely associated with active commuting to school $(\beta=-0.008, \mathrm{SE}=0.004, \mathrm{P}=0.03)$, while mixed-land use was positively associated with daily MPVA $(\beta=60.0, \mathrm{SE}=24.3$, $\mathrm{P}=0.02)$. There was effect modification such that high traffic volume and high street connectivity were associated with greater moderate-to-vigorous physical activity. The results of this study suggest that the built environment may play a role in active school commuting outcomes and daily physical activity.
\end{abstract}

Keywords: built environment, children, geographical information systems, active commuting, physical activity, United States of America.

\section{Introduction}

The built environment has been shown to influence children's physical activity, and built environments that promote walking and other forms of physical activity have been offered as one way to maximise children's physical activity (Davison and Lawson, 2006; Saelens and Handy, 2008; Giles-Corti et al., 2009; Ding et al., 2011). Walking to school represents a population level activity that could improve physical activity in youth and help combat obesity (U.S. Department of Health and Human Services, 2012).

Active commuting (walking or cycling) to school has been associated with increased overall physical activity and decreased adiposity in youth (Lee et al., 2008;

\footnotetext{
Corresponding author: Nicolas M. Oreskovic

Center for Child \& Adolescent Health Research and Policy 100 Cambridge Street, $15^{\text {th }}$ floor, Boston, MA 02114, USA Tel. +1 617 726-0593; Fax +1 617 726-1886

E-mail: noreskovic@mgh.harvard.edu
}

Lubans et al., 2011; Mendoza et al., 2011b). A "walking school bus" is a neighbourhood programme where children walk to and from school led by (an) adult chaperone(s). Walking school buses have become increasingly popular among localities seeking to increase childhood physical activity and active commuting to school (ACS). When studied empirically, walking school buses have been shown to increase children's ACS and overall daily physical activity levels (Mendoza et al., 2011a). Certain attributes of the physical environment may play a role in parent's decisions surrounding ACS, as well as in children's decisions on whether to walk to school. These built environment factors may influence decisions on active commuting beyond simple availability of a walking school bus programme. The goal of this study was to examine the role of the environment on a walking school bus pilot randomised controlled trial (RCT). We used geographical information systems (GIS) to map and analyse the environments around schools participating in a walking school bus pilot RCT, as well as the environments along walking routes, to bet- 
ter contextualise the environments in which the RCT occurred and determine the importance of environmental context on the study outcomes. We hypothesised that attributes of built environment previously shown to be associated with ACS and physical activity in youth in cross-sectional studies would predict changes to children's ACS at follow-up. Given the well-described association between ACS and daily physical activity, we further aimed to test whether any built environment attributes along walking routes predicted overall daily moderate-to-vigorous physical activity (MVPA) levels.

In this current study, we use subject data obtained from a RCT walking school bus study conducted in Houston, Texas, United States of America (USA) in 2009 (Mendoza et al., 2011a), along with newly collected geospatial data to test whether surrounding built environments predict physical activity. Subject data collected during the original RCT included daily school commute type (walking versus motorised), daily physical activity levels, subject height and weight and a subject's socioeconomic information. All geospatial data, including all GIS and built environment data and analyses, were collected as new data for this study and analysed for the first time in this study.

\section{Materials and methods}

This study used an observational, cross-sectional design to examine the role of the built environment on outcomes of a walking school study conducted in Houston, USA in 2009. Full details of the original walking school busy study, including the study population, study design and outcomes, have been previously published (Mendoza et al., 2011a).

\section{Participants}

One hundred and forty-nine low-income children in the $4^{\text {th }}$ grade who had participated in the walking school bus RCT and lived within one mile of school were included in this study. Children in the intervention group attended one of four intervention schools, with children in the control group from four control schools. The mean age was 9.7 years, $47.0 \%$ were male, $2.7 \%$ non-Hispanic White, $30.9 \%$ nonHispanic Black and $62.4 \%$ Hispanic/Latino with $58.4 \%$ of parent participants being born outside the USA. There were no statistical differences between any of the above baseline participant characteristics in the control and intervention groups (Mendoza et al. 2011a). The study was approved by the institutional review board of Baylor College of Medicine and the Research Department of the Houston Independent School District.

\section{Walking school bus intervention}

In the walking school bus study, schools were matched according to race/ethnicity and socioeconomic status and randomly assigned to the intervention $(\mathrm{n}=4)$ or control $(\mathrm{n}=4)$ condition. Intervention schools had one to three walking routes based on children's home addresses. The control schools received the usual information provided by the school district on school transportation and were free to commute to school as they wished.

\section{Outcome variables}

The primary outcome variable in the original walking school bus study was the change in percentage of trips made by ACS over one school week (percent ACS). This was assessed every school day for each subject for one week at baseline (prior to randomisation) and at follow-up (during weeks 4 and 5 of the programme) using a validated instrument (Mendoza et al., 2009). The secondary outcome in the walking school bus study was change in MVPA (min per day) measured by accelerometry (ActiGraph GT1M, Pensacola, USA), with a valid day defined as $\geq 10$ hours of wear per day and MVPA categorised by agespecified thresholds set at four metabolic equivalents (Freedson et al., 1997). For this study, both percent ACS and MVPA at the subject level were retained as the primary and secondary outcome variables, respectively.

\section{GIS variables}

Built environment attributes were considered static since the original study was evaluated over a brief time period of 5-6 weeks. ArcGIS version 10.0 (ESRI; Redlands, USA) was used to map the environments around the study schools and along walking routes for intervention and control subjects. Attributes of the built environment available in GIS, which might plausibly influence a parent's decision to allow ACS and a child's decision to walk to school, were included. These included the following nine variables: presence of sidewalks, land-use mix, street connectivity, traffic volume, traffic signals, police presence, bicycle paths, major roads and parks (Kerr et al., 2006; Larsen et al., 2009; Mecredy et al., 2011; Wong et al., 2011; Giles- 
Corti et al., 2011). Sidewalks, presence and width in meters (m), were obtained from Google Earth basemaps using aerial photography. For land-use mix, parcel and zoning data were obtained from the Harris County Appraisal District and the Neighbourhood Environment for Active Transport-GIS protocols were then used to determine land-use mix and to create a dissimilarity index to measure the degree to which different land-uses exist. Values ranged from 0 (perfect similarity of all surrounding land use categories) to 1 (complete dissimilarity) as described by Forsyth (2012). Street connectivity was created with the ESRI ArcMap software using ArcToolbox and recorded as the number of intersections based on street centrelines obtained from the City of Houston GIS. Traffic volume, recorded as counts, were obtained from Houston TranStar (http://www.houstontranstar.org/). Traffic signals data, recorded as numerical data, were obtained from the City of Houston Department of Public Works and Engineering. Police presence (density of police stations and neighbourhood storefronts) was obtained from the City of Houston Geographical Information \& Management system (http://www.gims. houstontx.gov/PortalWS/MainPortal.aspx) as was the extent and width of bicycle lanes (m), major roads (m) and parks $\left(\mathrm{m}^{2}\right)$.

We created buffers around the schools and around the walking routes to map the surrounding built environments using GIS (Fig. 1). For schools, we first geocoded the schools based on address and then created buffers using both straight lines and street networks (Oliver et al., 2007), creating 400-, 800- and 1,600-m (the latter roughly 1 mile) buffers. Four and $800-\mathrm{m}$ are considered proximal neighbourhood environments for children (Timperio et al., 2004; Colabianchi et al., 2009), and 1,600-m has been used to validate children's walking environments using GIS, which led to all three buffer sizes being used in the analyses (Duncan et al., 2011). For walking routes, intervention schools' buffers were created around the routes children walked along during the RCT. For control schools, each child's home address was geocoded, and the route was the shortest distance from home to school using street networks. For all walking routes to school, we created straight-line buffers around the street centrelines running along the street networks to determine the presence of built environmental variables. We used 50-m buffers to assess the environments around the walking routes (Duncan et al., 2011) for all GIS variables except dissimilarity index, which used 200-m buffers, and traffic counts, which required 2,000-m buffers since these counts were only recorded in specific, predetermined cross-streets often falling outside the smaller buffers.

\section{Covariates}

Subject covariates which were collected as part of the original RCT in 2009 and included in this study were as follows. Height and weight were measured in duplicate by trained research staff following a standardised protocol. The body mass index (BMI, $\mathrm{kg} / \mathrm{m}^{2}$ ) was calculated from the mean of the two measured heights and weights, and Centers for Disease Control and Prevention (CDC) growth charts were used to calculate BMI $z$-scores (Kuczmarski et al., 2002). Parents
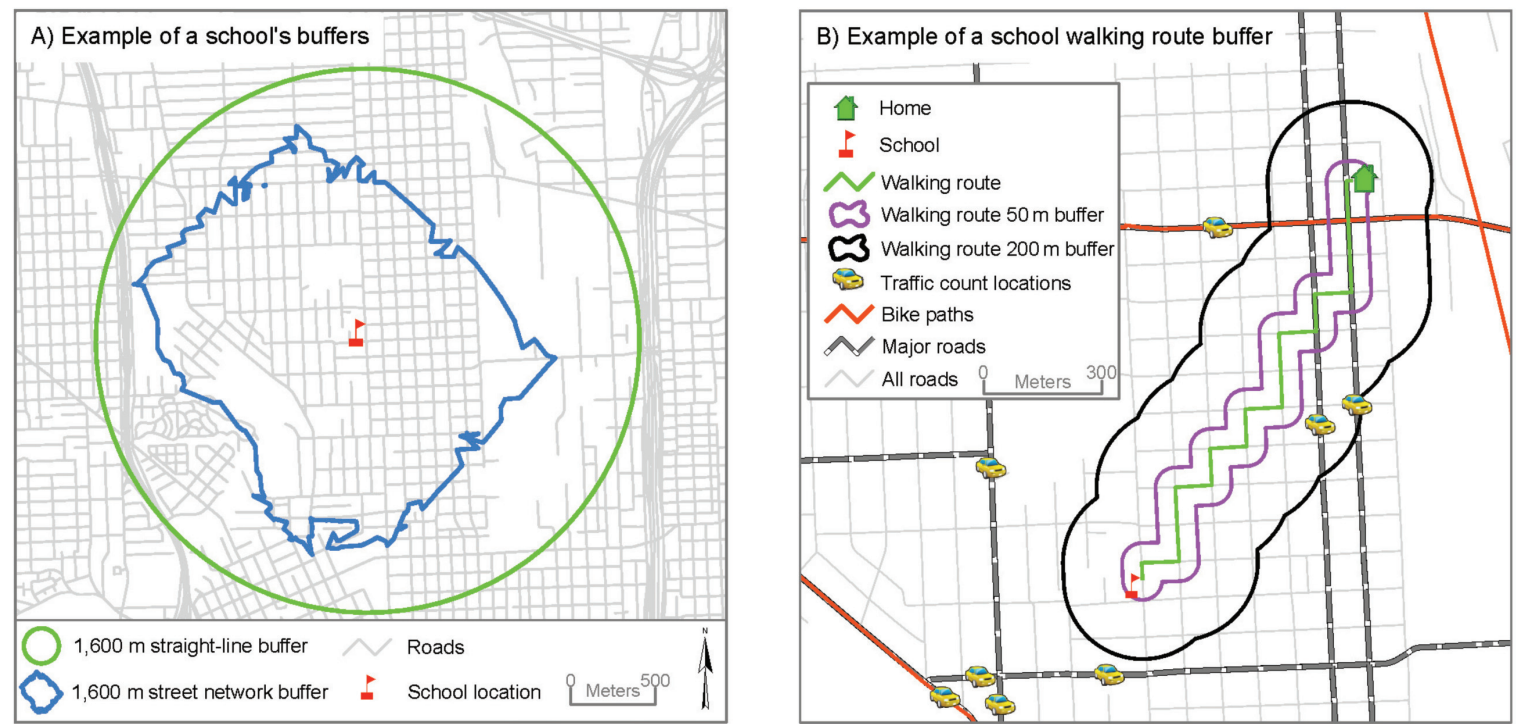

Fig. 1. GIS maps showing examples of a school buffer and a walking route buffer. 
completed a socio-demographic survey, which provided age (years), gender, race/ethnicity (non-Hispanic White, non-Hispanic Black, Hispanic, other), highest level of household education, annual household income and home address. Acculturation, i.e. the process of adopting the cultural traits or social patterns of another group, previously shown to be associated with Latino children's mode of transport to school in cross-sectional studies, was obtained from several proxies (parent and child's country of birth, parent and child's length of residence in the USA) which were summed to provide a global measure (Martinez, et al., 2008; Mendoza et al., 2010). Safety was assessed using a subscale from the Neighbourhood Environment for Children Rating Scales (Coulton et al., 1996). Children's self-efficacy for ACS, and parent's self efficacy for allowing their children to do ACS, along with parents' outcome expectations were assessed using self-reported questionnaires according to Cronbach's $\alpha=0.75,0.88$ and 0.78, respectively (Mendoza et al., 2010, 2011a). These constructs were associated with children's ACS in previous studies (Mendoza et al., 2010, 2011a).

\section{Statistical analysis}

We first conducted school-level analyses using descriptive statistics to report the presence of built environment variables in the buffers surrounding the eight intervention and control schools. Analyses of variance (ANOVA) was used to compare the mean presence of environmental factors in intervention and control schools within the straight-line and street network buffers.

To determine the importance of the built environment on ACS, we then conducted student-level analyses using multi-level mixed models accounting for repeated measures with school, route and individual child included as random effects to test for the presence of significant built environment variables along walking routes. Two separate models were run: one with percent ACS (the primary outcome of the RCT) and one with min per day of MVPA (the secondary outcome) as the dependent variable. Independent variables included the nine built environment variables mapped in GIS, study subject, school route and study status (control versus intervention). An interaction term between street connectivity and traffic volume was included in the models. Covariates included age, gender, race/ethnicity, parental education, family income, neighbourhood safety, acculturation and distance from home. Mediating variables (child self-effi- cacy and parent self-efficacy) were included in the model for percent ACS only. Stepwise procedures with backward elimination of non-significant $(\mathrm{P}>0.1)$ covariates identified significant predictors. A Markov chain Monte Carlo algorithm was used to impute missing data for non-GIS data only (Yuan, 2000). The continuous variables street connectivity and traffic volume were then further categorised as binary variables based on median values to allow for testing of the estimated marginal means to better describe the interactions between street connectivity and traffic volume.

\section{Results}

Comparing the surrounding environments of control with intervention schools, using both straight-line and street-network buffers, we found no statistically significant differences in the presence of the nine built environment features at $400-\mathrm{m}$ or $800-\mathrm{m}$ (data not shown). For 1,600-m buffers, only the amount of park space approached significance, with intervention schools having more surrounding park space $\left(146,121 \mathrm{~m}^{2}\right.$ versus $\left.551,344 \mathrm{~m}^{2}, \mathrm{P}=0.09\right)$, as measured by straight-line buffers (Table 1 ). No differences were present using 1,600-meter street-network buffers.

Looking at the built environments along school routes, we found several different attributes of the built environment to be significant predictors for the primary outcome (ACS) as well as for the secondary outcome (MVPA) (Table 2). For ACS, we found that the amount of park space $(\mathrm{P}=0.03)$ along school routes was inversely associated with ACS. No other built environment features present along school routes predicted the ACS outcomes. After adjusting for these possible built environment features, we also did not find any personal or family characteristics to be predictive of whether a child did ACS. For predicting longitudinal physical activity, younger age $(\mathrm{P}=0.01)$ and being male $(\mathrm{P}=0.002)$ were associated with greater daily MVPA, as were walking along school routes with increased mixed-land use $(P=0.02)$, less street connectivity $(\mathrm{P}=0.04)$, and lower traffic volume $(\mathrm{P}=0.04)$. In addition, there was evidence of effect modification between street connectivity and traffic volume $(\mathrm{P}=0.02)$. Along school routes with low traffic volume, there was no difference in MVPA between routes with high or low street connectivity. Along school routes with high traffic volume, high street connectivity was associated with greater MVPA (53 min) than low street connectivity (35 min) (Fig. 2). No asso- 
Table 1. School-level analyses comparing presence of environmental factors within school buffers.

\begin{tabular}{|c|c|c|c|c|c|c|}
\hline \multirow[b]{2}{*}{$\begin{array}{l}\text { Built environmental } \\
\text { variable }\end{array}$} & \multicolumn{3}{|c|}{$1,600 \mathrm{~m}$ radial buffer (mean) } & \multicolumn{3}{|c|}{ 1,600 m street-network buffer (mean) } \\
\hline & $\begin{array}{c}\text { Control } \\
\text { schools }(n=4)\end{array}$ & $\begin{array}{l}\text { Intervention } \\
\text { schools }(n=4)\end{array}$ & P-value & $\begin{array}{c}\text { Control } \\
\text { schools }(n=4)\end{array}$ & $\begin{array}{c}\text { Intervention } \\
\text { schools }(n=4)\end{array}$ & P-value \\
\hline Sidewalk (m) & 29,178 & 36,957 & 0.47 & 63,318 & 66,566 & 0.83 \\
\hline Land-use mix & 0.37 & 0.34 & 0.43 & 0.35 & 0.36 & 0.83 \\
\hline Street connectivity & 459 & 352 & 0.15 & 252 & 209 & 0.41 \\
\hline Traffic volume & 168,987 & 224,769 & 0.51 & 80,173 & 123,886 & 0.30 \\
\hline Traffic signals & 18.8 & 13.3 & 0.26 & 10.5 & 8.8 & 0.59 \\
\hline Police & 0.5 & 0.5 & 1.00 & 0 & 0.5 & 0.13 \\
\hline Bicycle paths $(\mathrm{m})$ & 9,472 & 7,773 & 0.56 & 4,209 & 3,445 & 0.65 \\
\hline Major roads $(\mathrm{m})$ & 16,120 & 13,735 & 0.45 & 8,628 & 8,069 & 0.78 \\
\hline Parks $\left(\mathrm{m}^{2}\right)$ & 146,121 & 551,344 & 0.09 & 73,059 & 122,924 & 0.24 \\
\hline
\end{tabular}

Highly significant results in bold.

ciations were found between sidewalks, traffic signals, police presence, bicycle paths or major roads and ACS or physical activity.

\section{Discussion}

This study is the first to contextualise the surrounding built environments of schools participating in a walking school bus RCT and to identify potential environmental attributes using GIS which may play a role in walking school bus outcomes. We found that despite schools having similar surrounding built environments, differences in the built environment along school routes were significantly associated with frequency of active commuting to school and overall daily MVPA. Presence of park space predicted lower
ACS, while greater mixed land-use was associated with higher daily MVPA. Street connectivity and traffic volume were associated with daily MVPA such that school routes with higher traffic volume and higher street connectivity were associated with achieving on average 18 more min of daily MVPA than routes with high street volume but low connectivity. There was no difference in MVPA along school routes with lower traffic volume, regardless of street connectivity.

There are several important findings and the study begins to provide much needed experimental data on the importance of the built environment on changes with respect to physical activity behaviour. These findings have the potential to offer important guidance to planners and designers, who have the ability to influence physical activity levels in society through the

Table 2. Student-level multivariable analyses of environmental factors along school routes predicting active commuting and physical activity.

\begin{tabular}{|c|c|c|c|c|c|c|}
\hline \multirow[b]{2}{*}{$\begin{array}{l}\text { Built environmental } \\
\text { variable }\end{array}$} & \multicolumn{3}{|c|}{ Active commuting to school ${ }^{a}$} & \multicolumn{3}{|c|}{$\mathrm{MVPA}^{\mathrm{b}}$} \\
\hline & $\begin{array}{l}\text { Regression } \\
\text { coefficient }\end{array}$ & $\begin{array}{l}\text { Standard } \\
\text { error (SE) }\end{array}$ & P-value & $\begin{array}{l}\text { Regression } \\
\text { coefficient }\end{array}$ & $\begin{array}{l}\text { Standard } \\
\text { error }(S E)\end{array}$ & P-value \\
\hline Sidewalk & 0.003 & 0.007 & 0.64 & 0.002 & 0.005 & 0.66 \\
\hline Land-use mix & 17.8 & 34.8 & 0.61 & 60.0 & 24.3 & 0.02 \\
\hline Street connectivity & -3.84 & 4.02 & 0.34 & -5.57 & 2.62 & 0.04 \\
\hline Traffic volume & 0.001 & 0.003 & 0.62 & -0.003 & 0.002 & 0.04 \\
\hline Street connectivity $\mathrm{x}$ traffic volume & -0.00005 & 0.0002 & 0.84 & 0.0004 & 0.0002 & 0.02 \\
\hline Traffic signals & 1.85 & 9.66 & 0.85 & 0.68 & 5.68 & 0.91 \\
\hline Police & - & - & - & - & - & - \\
\hline Bicycle paths & 0.005 & 0.020 & 0.98 & -0.03 & 0.02 & 0.07 \\
\hline Major roads & 0.02 & 0.02 & 0.39 & 0.02 & 0.01 & 0.23 \\
\hline Parks & -0.008 & 0.004 & 0.03 & -0.0009 & 0.002 & 0.73 \\
\hline
\end{tabular}

a Model adjusted for distance, parent acculturation, parent outcome expectations, study group, study period and the interaction between study group and study period; bmoderate-to-vigorous physical activity; highly significant results in bold. 


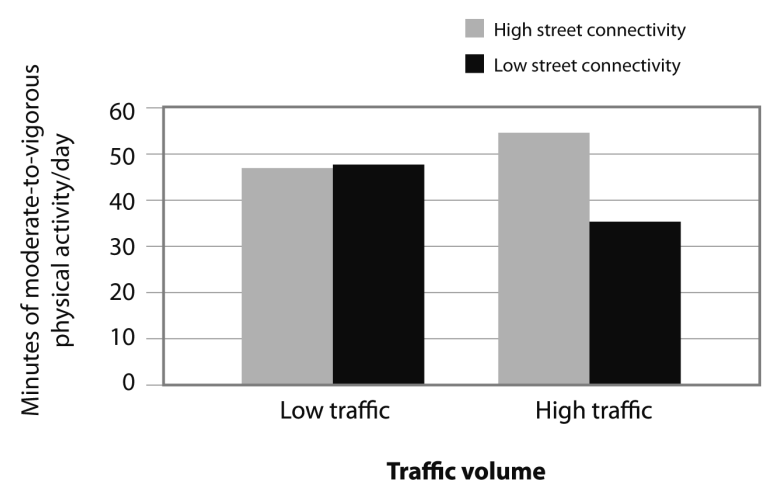

Fig. 2. The influence of street connectivity on children's daily physical activity, stratified by traffic volume.

spaces they design. Built environment variables were selected based on prior empiric work showing associations with physical activity and this study's findings complement a long history of planning and design theory on features purported to influence pedestrian behaviour and activity (Handy et al., 2002).

In contrast to previous cross-sectional studies reporting increased green space to be associated with physical activity (Potwarka et al., 2008; Jones et al., 2009; Lachowycz et al., 2012), this study found that having less park space along walking routes predicted higher ACS rates. Less park space may be an indication of a built environment with greater street coverage and a more developed urban infrastructure and higher population density (Fuller and Gaston, 2009), which may facilitate or encourage ACS. It is worth noting that distance to school did not significantly predict ACS, nor did traffic volume or traffic signals, suggesting parks are not simply a proxy for degree of "urbanicity". Moreover, the walking school bus programme may help overcome distance to school as a barrier to ACS. Many attributes of the built environment may influence travel patterns through related or convergent pathways. For example, the presence of a high degree of street intersections and a paucity of green space may be conceptually related to increased traffic counts. To distinguish between these potentially related concepts, we included and tested each specific environmental attribute, including street connectivity, parks and traffic volume, as separate predictor variables of longitudinal travel patterns, to determine any discrete pathways of action on commuting patterns. One other possible mechanism through which these related built environment concepts may impact commuting mode is through individual perceptions. Parental perception is known to play a role in children's school commute mode (Oreskovic et al., 2009), and parents may perceive less park space to indicate a more established urban infrastructure with fewer major roads and thereby a lower risk of traffic-related danger, which in turn may influence their decisions for allowing their child to do ACS.

No association was present between street connectivity and continued participation in a walking school bus programme, in contrast to prior cross-sectional studies (Timperio et al., 2006; Giles-Corti et al., 2011). Prior work has also found street connectivity to be inversely related to physical activity in children (Mecredy et al., 2011). The present study found evidence that traffic modifies the effect of street connectivity on MVPA, providing further insight into the complex relationship between the built environment and physical activity. One theory has been that increased street connectivity may correspond with higher traffic volumes, and thereby discourage physical activity. A study among Australian schoolchildren found that in neighbourhoods with high street connectivity, children were more likely to walk to school in regions with lower traffic volumes (Giles-Corti et al., 2011). Similarly, our findings of greater MPVA associated with higher street connectivity and greater traffic may be a reflection that environments containing high street connectivity and traffic represent easier opportunities for children to travel to areas where they may be physically active, especially if the children do so by walking or other active means. Additionally, high street connectivity and high traffic may simply reflect areas where it is easier for parents to transport their children to places where they can be physical active. These findings for ACS and overall physical activity raise important questions about whether specific attributes of the built environment promote physical activity differently depending on activity type. While prior studies have used cross-sectional data, this study used ACS and physical activity data from a RCT, providing some suggestion on the causal role of the built environment in determining ACS and physical activity patterns in children. Given the small sample size, and the secondary nature of these analyses, additional experimental studies are needed to better clarify the role of the built environment on childhood physical activity.

The study findings that younger children and boys were more likely to have higher daily MVPA are consistent with national physical activity patterns in the USA (Nader et al., 2008). Regarding other built environment attributes in addition to street connectivity and traffic volume, we found that children who 
walked along routes with increased mixed land-use also had greater overall daily MVPA levels. These findings are consistent with the existing literature on the role of mixed-land use in promoting walking and weight control (Rundle et al., 2007; Saelens and Handy 2008; Ding et al., 2011).

This study has several limitations. The school routes which control subjects walked along to get to school, if any, were not known, and were based on shortest street network walking distance to school. This is a logical approach which has been widely used in previous GIS-based research (Wong et al., 2011). Recent work using global positioning systems documenting children's travel patterns to school confirms that children follow direct connected street routes to school (Cooper et al., 2010). There may be other built environmental elements not available for GIS analysis in this study but which may contribute to a parent's decision to allow a child to participate in a walking school bus study. This study was conducted in one urban city in Texas, USA among low-income children, and findings may not be possible to generalise. The sample size is relatively small, which limits statistical power. The GIS analysis in this study was cross-sectional and the follow-up period of the original walking school bus study was brief - studies are necessary to examine influences on outcomes in the long-term.

Despite these caveats, this study has several strengths. Most prior studies using GIS to assess environmental correlates along school routes have used cross-sectional physical activity and school travel data (Wong et al., 2011), this study used travel data from a RCT to assess the contribution of the built environment to ACS. To our knowledge, this study is the first to report on the use of GIS to analyse the role of the built environment on the outcomes of a walking school bus RCT. We employed sophisticated statistical multi-level modelling accounting for possible random effects at the level of the individual, the school, and the surrounding environment. The findings are informative to planners and designers responsible for city design and infrastructure upkeep, and by shaping the environments which children use to obtain daily physical activity, have the capacity to result in a population-level shift in commuting patterns and physical activity levels.

\section{Conclusion}

The built environment played a role in children's active commuting to school and physical activity outcomes from a walking school bus study. Less park space along school routes was associated with more active commuting to school, while greater land-use mix, and school routes with both high street connectivity and high traffic volumes were associated with increased MVPA. Childhood physical activity and active travel interventions should consider the potential impact of the built environment.

\section{Funding}

N.M. Oreskovic was supported by a grant from the National Institutes of Health/National Heat, Lung, and Blood Institutes (K23HL103841). J.A. Mendoza was supported by grants from Active Living Research of the Robert Wood Johnson Foundation (grant 63773), the National Institutes of Health/National Cancer Institute (K07CA131178 and R21CA133418), and the United States Department of Agriculture (Cooperative Agreement 6250-51000-053). This work was presented in part as a poster at the Pediatric Academic Societies meeting, May 2013; Washington, D.C.

\section{References}

Colabianchi N, Kinsella AE, Coulton CJ, Moore SM, 2009. Utilization and physical activity levels at renovated and unrenovated school playgrounds. Prev Med 48, 140-143.

Cooper AR, Page AS, Wheeler BW, Griew P, Davis L, Hillsdon M, Jago R, 2010. Mapping the walk to school using accelerometry combined with a global positioning system. Am J Prev Med 38, 178-183.

Coulton CJ, Korbin JE, Su M, 1996. Measuring neighborhood context for young children in an urban area. Am J Commun Psychol 24, 5-32.

Davison KK, Lawson CT, 2006. Do attributes in the physical environment influence children's physical activity? A review of the literature. Int J Behav Nutr Phys Act 3, 19.

Ding D, Sallis JF, Kerr J, Lee S, Rosenberg DE, 2011. Neighborhood environment and physical activity among youth a review. Am J Prev Med 41, 442-455.

Duncan DT, Aldstadt J, Whalen J, Melly SJ, Gortmaker SL, 2011. Validation of Walk Score ${ }^{\circledR}$ for estimating neighborhood walkability: an analysis of four US metropolitan areas. Int J Environ Res Public Health 8, 4160-4179.

Forsyth A, 2012. NEAT-GIS (Neighborhood environment for active transport-geographic information systems): Version 5.1, 1-228. Available at: www.designforhealth.net/protocols.html (accessed on September 2012).

Freedson P, Sirard J, Debold E, Pate R, Dowda M, Trost S, Sallis J, 1997. Calibration of the computer science and applications, Inc. Accelerometer 256. Med Sci Sports Exerc 29, 45.

Fuller RA, Gaston KJ, 2009. The scaling of green space coverage in European cities. Biol Lett 5, 352-355. 
Giles-Corti B, Kelty SF, Zubrick SR, Villanueva KP, 2009. Encouraging walking for transport and physical activity in children and adolescents: how important is the built environment? Sports Med 39, 995-1009.

Giles-Corti B, Wood G, Pikora T, Learnihan V, Bulsara M, Van Niel K, Timperio A, McCormack G, Villanueva K, 2011. School site and the potential to walk to school: the impact of street connectivity and traffic exposure in school neighborhoods. Health Place 17, 545-550.

Handy SL, Boarnet MG, Ewing R, Killingsworth RE, 2002. How the built environment affects physical activity: views from urban planning. Am J Prev Med 23, 64-73.

Jones AP, Coombes EG, Griffin SJ, van Sluijs EM, 2009. Environmental supportiveness for physical activity in English schoolchildren: a study using global positioning systems. Int J Behav Nutr Phys Act 6, 42.

Kerr J, Rosenberg D, Sallis JF, Saelens BE, Frank LD, Conway TL, 2006. Active commuting to school: associations with environment and parental concerns. Med Sci Sports Exerc 38, 787-794.

Kuczmarski RJ, Ogden CL, Guo SS, Grummer-Strawn LM, Flegal KM, Mei Z, Wei R, Curtin LR, Roche AF, Johnson CL, 2002. 2000 CDC growth charts for the United States: methods and development. Vital Health Stat 11, 1-190.

Lachowycz K, Jones AP, Page AS, Wheeler BW, Cooper AR, 2012. What can global positioning systems tell us about the contribution of different types of urban greenspace to children's physical activity? Health Place 18, 586-594.

Larsen K, Gilliland J, Hess P, Tucker P, Irwin J, He M, 2009. The influence of the physical environment and sociodemographic characteristics on children's mode of travel to and from school. Am J Public Health 99, 520-526.

Lee MC, Orenstein MR, Richardson MJ, 2008. Systematic review of active commuting to school and childrens physical activity and weight. J Phys Act Health 5, 930-949.

Lubans DR, Boreham CA, Kelly P, Foster CE, 2011. The relationship between active travel to school and health-related fitness in children and adolescents: a systematic review. Int J Behav Nutr Phys Act 8, 5.

Martinez SM, Ayala GX, Arredondo EM, Finch B, Elder J, 2008. Active transportation and acculturation among Latino children in San Diego county. Prev Med 47, 313-318.

Mecredy G, Pickett W, Janssen I, 2011. Street connectivity is negatively associated with physical activity in Canadian youth. Int J Environ Res Public Health 8, 3333-3350.

Mendoza JA, Levinger DD, Johnston BD, 2009. Pilot evaluation of a walking school bus program in a low-income, urban community. BMC Public Health 9, 122.

Mendoza JA, Watson K, Baranowski T, Nicklas TA, Uscanga DK, Hanfling MJ, 2011a. The walking school bus and chil- dren's physical activity: a pilot cluster randomized controlled trial. Pediatrics 128, e537-e544.

Mendoza JA, Watson K, Baranowski T, Nicklas TA, Uscanga DK, Nguyen N, Hanfling MJ, 2010. Ethnic minority children's active commuting to school and association with physical activity and pedestrian safety behaviors. J Appl Res Child 1, 1-23.

Mendoza JA, Watson K, Nguyen N, Cerin E, Baranowski T, Nicklas TA, 2011b. Active commuting to school and association with physical activity and adiposity among US youth. J Phys Act Health 8, 488-495.

Nader PR, Bradley RH, Houts RM, McRitchie SL, O’Brien M, 2008. Moderate-to-vigorous physical activity from ages 9 to 15 years. JAMA 300, 295-305.

Oliver LN, Schuurman N, Hall AW, 2007. Comparing circular and network buffers to examine the influence of land use on walking for leisure and errands. Int J Health Geogr 6, 41.

Oreskovic NM, Sawicki GS, Kinane TB, Winickoff JP, Perrin JM, 2009. Travel patterns to school among children with asthma. Clin Pediatr (Phila) 48, 632-640.

Potwarka LR, Kaczynski AT, Flack AL, 2008. Places to play: association of park space and facilities with healthy weight status among children. J Community Health 33, 344-350.

Rundle A, Roux AV, Free LM, Miller D, Neckerman KM, Weiss CC, 2007. The urban built environment and obesity in New York City: a multilevel analysis. Am J Health Promot 21, 326334.

Saelens BE, Handy SL, 2008. Built environment correlates of walking: a review. Med Sci Sports Exerc 40, S550-S566.

Timperio A, Ball K, Salmon J, Roberts R, Giles-Corti B, Simmons D, Baur LA, Crawford D, 2006. Personal, family, social, and environmental correlates of active commuting to school. Am J Prev Med 30, 45-51.

Timperio A, Crawford D, Telford A, Salmon J, 2004. Perceptions about the local neighborhood and walking and cycling among children. Prev Med 38, 39-47.

U.S. Department of Health and Human Services, 2012. Physical activity guidelines for Americans Midcourse Report Subcommittee of the President's Council on Fitness, Sports \& Nutrition. Physical activity guidelines for Americans Midcourse Report: strategies to increase physical activity among youth. Washington, DC.

Wong BY, Faulkner G, Buliung R, 2011. GIS measured environmental correlates of active school transport: a systematic review of 14 studies. Int J Behav Nutr Phys Act 8, 39.

Yuan Y, 2000. Multiple imputation for missing data: concepts and new development, version 9.0. Available at: http://support.sas.com/rnd/app/papers/abstracts/multipleimputation.html (accessed on June 2010). 